
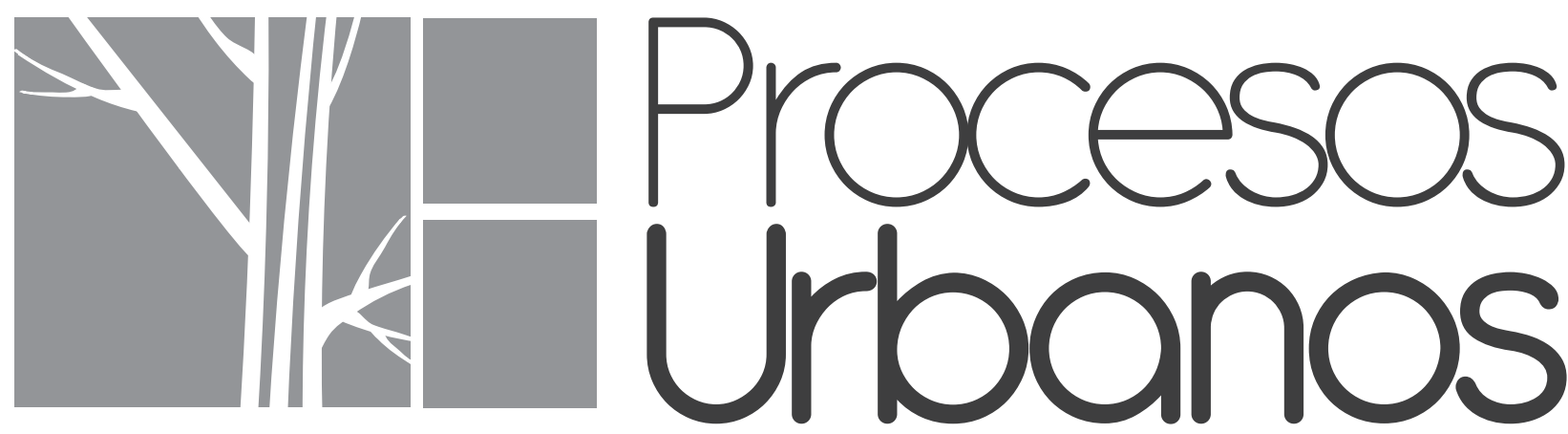

Revista de Divulgación Científica 


\section{Revista Procesos Urbanos}

Facultad de Ciencias Básicas, Ingeniería y Arquitectura.

ISSN: 2422-085X

Sincelejo, Enero - Diciembre de 2014

Piedad Martínez Carazo

Rectora

\section{Lidia Flórez de Albis}

Vicerrectora Académica

\section{Jhon Víctor Vidal}

Director de Investigaciones

\section{Pedro Arturo Martínez Osorio}

Editor

\section{Comité Editorial:}

PhD. Alexander Niño Soto. Universidad Antonio Nariño

PhD. Jorge Ramírez Nieto. Universidad Nacional de Colombia

Msc. Juan Carlos Pergolis. Universidad Católica de Colombia

PhD. Piedad Martínez Carazo. Corporación Universitaria del Caribe, CECAR

PhD. Emiro F. Martínez. Universidad de York, Canadá

\section{Comité Científico:}

Msc. Gloria Aponte García. UPB, Medellín

Msc. Jorge Vásquez Muñoz. UPB, Medellín

PhD. Jorge Gómez Ricardo, Universidad del Magdalena

\section{Editorial CECAR}

\section{Libia Narváez Barbosa}

Coordinadora Editorial

\section{Eduardo Támara Galván}

Corrector de Estilo

\section{Alejandrina Jaramillo y Roger Goez Castillo}

Diseño Gráfico

Diagramación e Impresión:GRÁFICAS DEL CARIBE S.A.S.

Cra. 1B No. 40-42 Montería Tel. (57) (4) 7826622 Telefax (57) (4) 7817112

Email: diseno@graficaribe.co

\section{Dirección:}

Carretera Troncal de Occidente

Kilómetro 1 Vía a Corozal

Tel: 280402928040172804018 Ext 1115

www.cecar.edu.co

http://cecar.edu.co/revista-procesos-urbanos 


\title{
EL ESPACIO PÚBLICO, UN DIBUJO DE LAS PERSONAS Evolución del concepto de ciudad, nuevos entornos urbanos
}

\author{
PUBLIC SPACE, A DRAWING OF PEOPLE \\ Evolution of the concept of city, new urban environments
}

José Manuel dos Santos Afonso ${ }^{1}$

Fecha: Recibido marzo 3 de 2014 / Aceptado abril 28 de 2014

\section{RESUMEN}

Este documento refleja la existencia de dibujos del tiempo, que quedan en nuestro interior para siempre, en el recuerdo, en la memoria, pero nunca en el olvido. La creatividad de las nuevas evoluciones de las ciudades latinas, contienen una plataforma de experiencias emotivas, encontrando en la verdadera historia de sus centros históricos, su diversidad e identidad propias. Con imaginación, debemos construir para que las personas sean simplemente felices en esos nuevos paisajes urbanos.

Palabras Clave: Diseño urbano, ciudad digital, patrimonio, antípolis, felicidad integrada.

\begin{abstract}
This document reflects the existence of drawings of the time, remaining within us forever, in remembrance, in memory, but never forgotten. The creativity of the new evolutions of the Latin cities, which contain a platform of experiences emotional, finding in the true story of their historical centres, its diversity and identity. With imagination, we must build so that people are simply happy in these new urban landscapes.
\end{abstract}

Keywords: Urban design, digital city, heritage, antipolis, integrated happiness.

1Arquitecto, Master - Arquitectura Militar en Portugal, PhD - Arquitectura Bancaria en Portugal; profesor de la Facultad de Arquitectura, Universidad de Lisboa, Portugal 
PROCESOS URBANOS - Revista de Divulgación Científica Vol. 1 Enero - Diciembre 2014 (7 - 16)

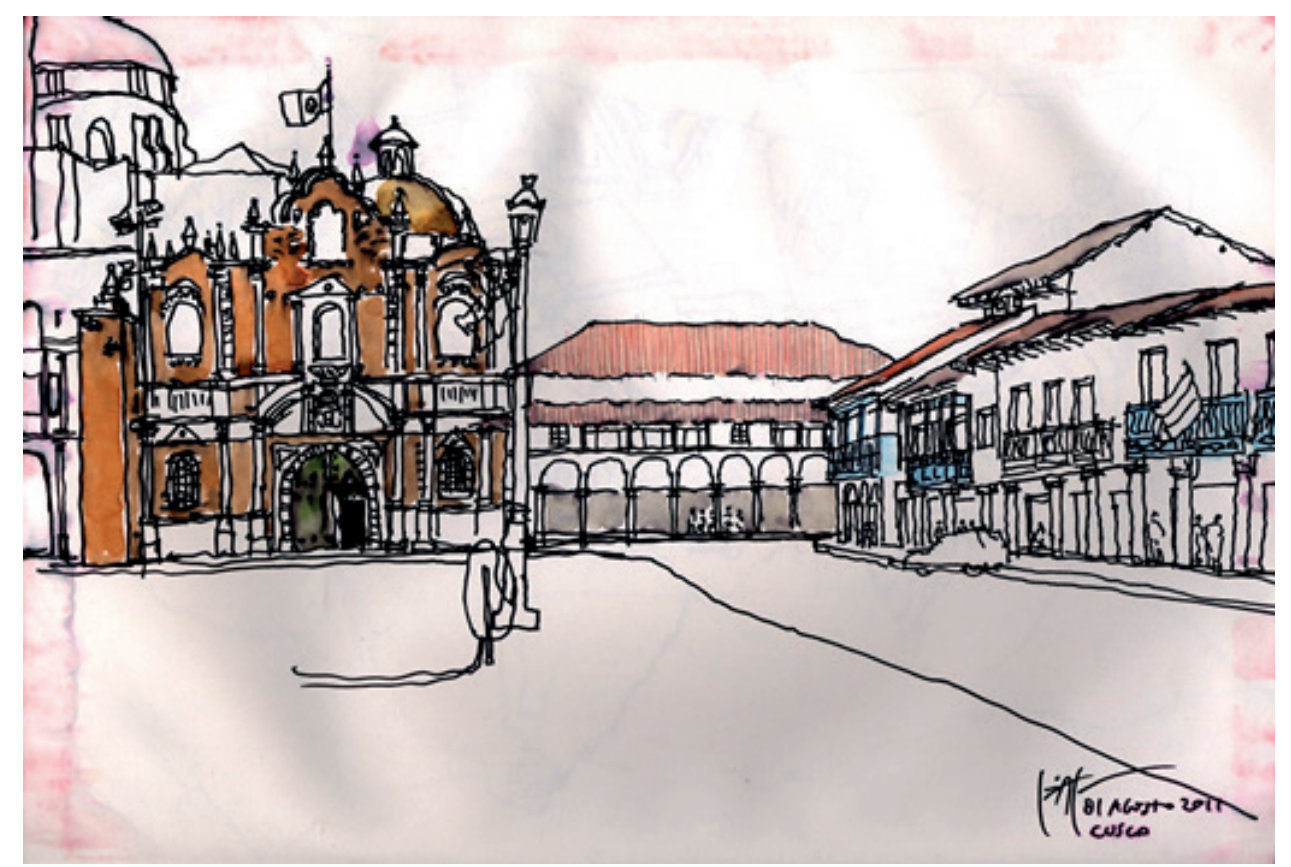

Figura 01 Acuarela. Cuzco, Perú, 2011 (Imagen del autor)

\section{INTRODUCCIÓN}

El proceso urbano siempre tendrá distintos caminos, definidos por las necesidades humanas de vivir en conjunto, y de las relaciones entre las diferentes sociedades en su contexto antropológico.
Sin embargo en los diferentes sitios (lugares) la evolución urbana, se dio a diferente velocidad y esa realidad se refleja en la organización, concentración, y densidad, en donde el factor tiempo, reúne en varios puntos de encuentro a la población, al territorio, la geografía y los intereses políticos, unidos

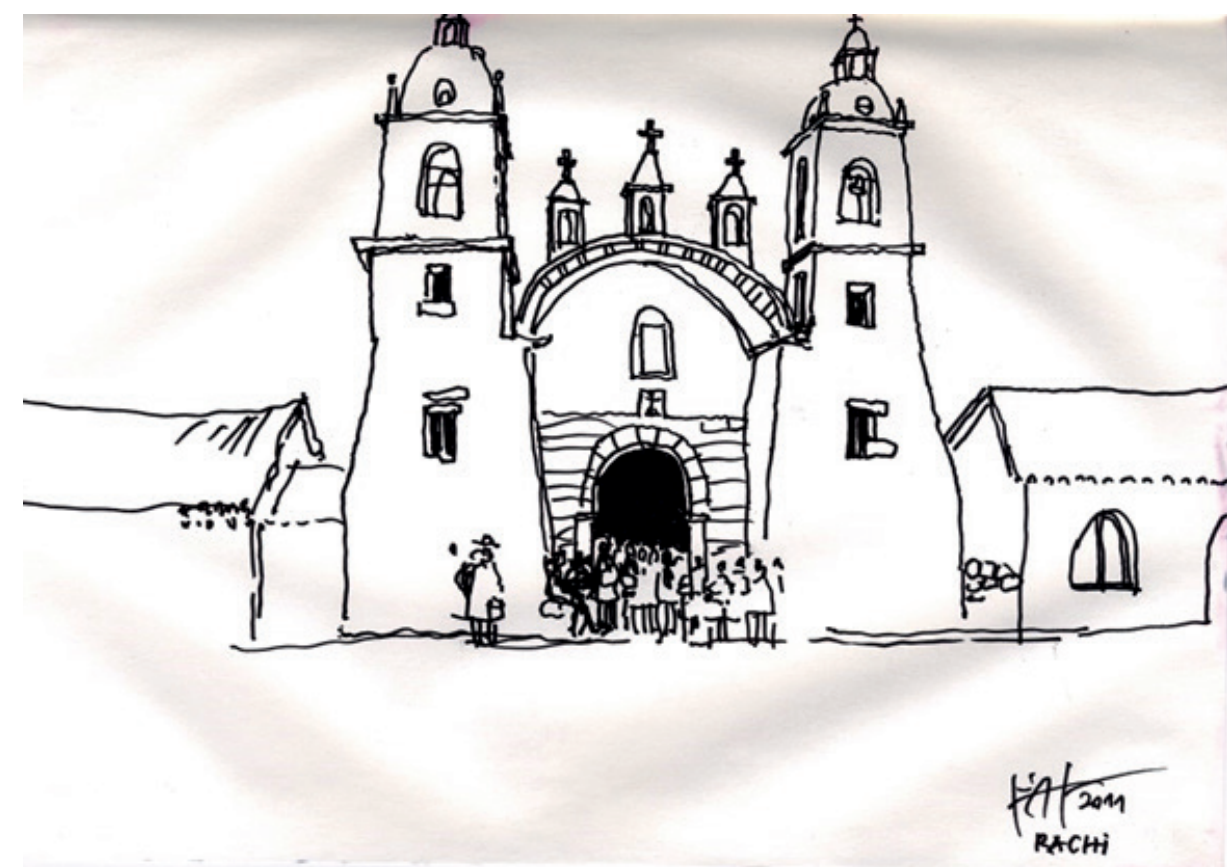

Figura 02 Perspectiva, Cuzco, 2011 (Imagen del autor). 
con los recursos, dirigidos hacia un espacio determinado, resultado de la convergencia de intereses de la gente o de personas con poder político, religioso o económico.

Rosa, (2002, pág. 247), habla sobre este tema en los siguientes términos "...también

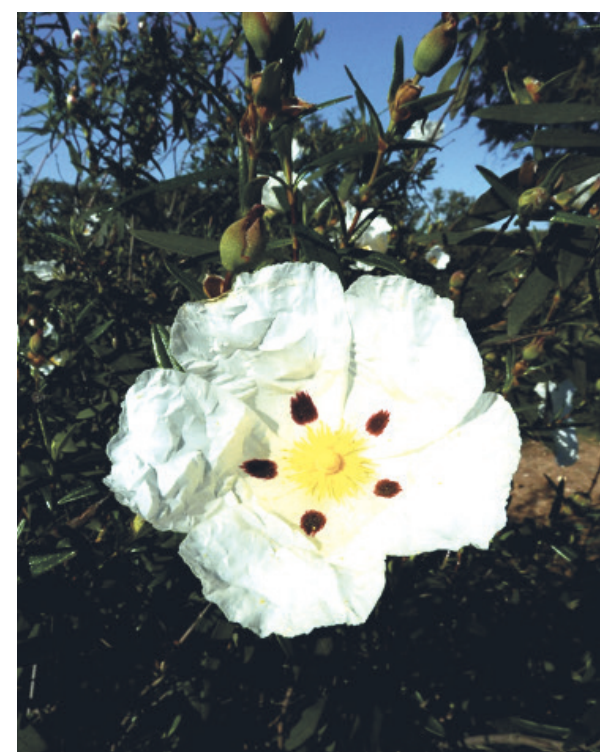

Figura 03 Naturaleza, 2011 (Imagen del autor)

espacios ocultando sus rituales e intentando mantener sus formas de vida, no es menos cierto que el espacio público que les era exclusivo dejó de estar separado del resto...".

Tenemos por un lado el espacio natural (disminuido por las presiones económicas),

\section{ENERGY NEEDS + CO2}

CIDADE DIGITAL
DIGITAL CITY

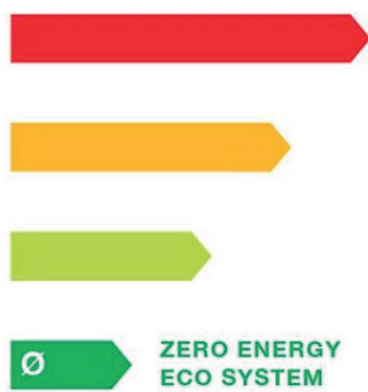

CIDADE TRADICIONAL TRADICIONAL CITY

ESPACO RURAL
COUNTRY

NATURAL

$\varnothing$

ECO SYSTEM directamente relacionado con las profundas mutaciones estructurales de la sociedad, identificables con la contra-reforma, está el final formal de los guetos étnicos; en efecto, juderías y morarías han dejado forzosamente de existir, y si en realidad esas comunidades han permanecido en sus

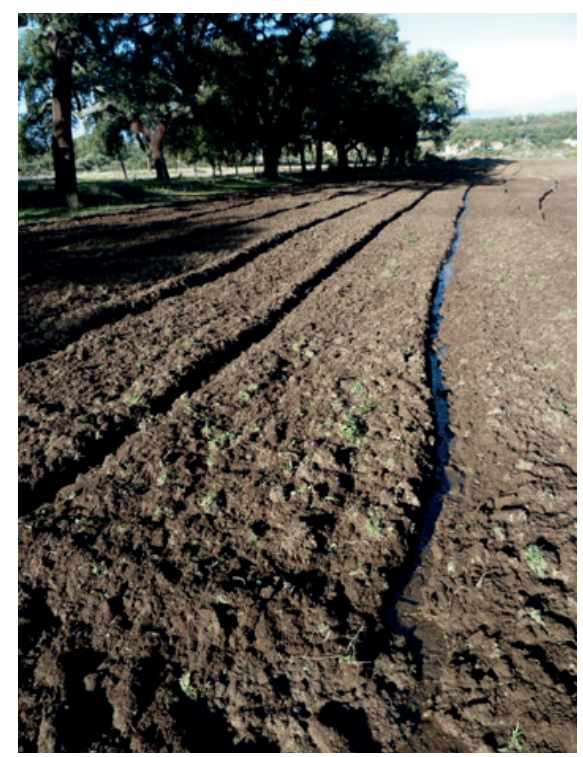

Figura 04 Espacio rural, 2012. (Imagen del autor)

por otro: el espacio urbano, y entre ellos existen unas líneas de infraestructuras físicas que se cruzan, Días (2006) lo explica en los siguientes términos "reconocen a las ciudades como un lugar de intercambio entre hombres. El territorio de lo imprevisible y de la maravillosa diversidad. La diversidad de los horarios, de los deseos, de las uniones,

\section{NATURAL
NATURE COUNAR CIDADE}

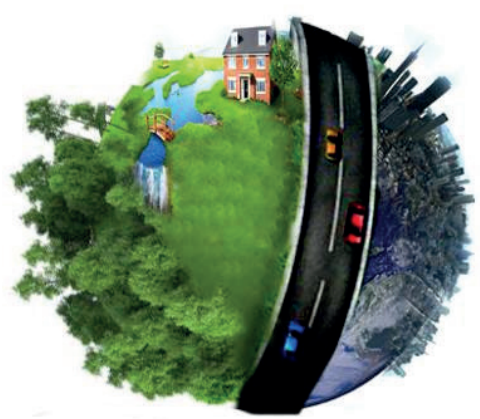

Figura 06 Esquema naturaleza + rural + ciudad, 2013. (Imagen del autor)

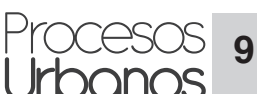


los arreglos, los encuentros" (Dias, 2006, pág. 73), es así que se cruzan en diferentes direcciones, y está el espacio aéreo (que casi nunca interfiere físicamente con lo rural y natural).

También tenemos el hecho que la ciudad contribuye con el consumo energético en grandes proporciones, es por esta razón que no se puede considerar una tecnología tan limpia, energéticamente hablando; como se divulga y se le quiere hacer ver, la ciudad digital necesita de grandes cantidades de energía para sobrevivir, y no será sustentable si sigue así, como ha sido conocida, para bien o mal, la ciudad Ilamada tradicional.

La gran diferencia entre el desarrollo de las ciudades de influencia portuguesa y española, y las ciudades anglo-sajonas adviene de su vivencia y de su cultura, de la ocupación del suelo urbano. Por un lado la ciudad más emotiva, más compleja, aparentemente más caótica, tal vez con influencia mediterránea, tiene su arquetipo en la ciudad griega y en la ciudad romana,

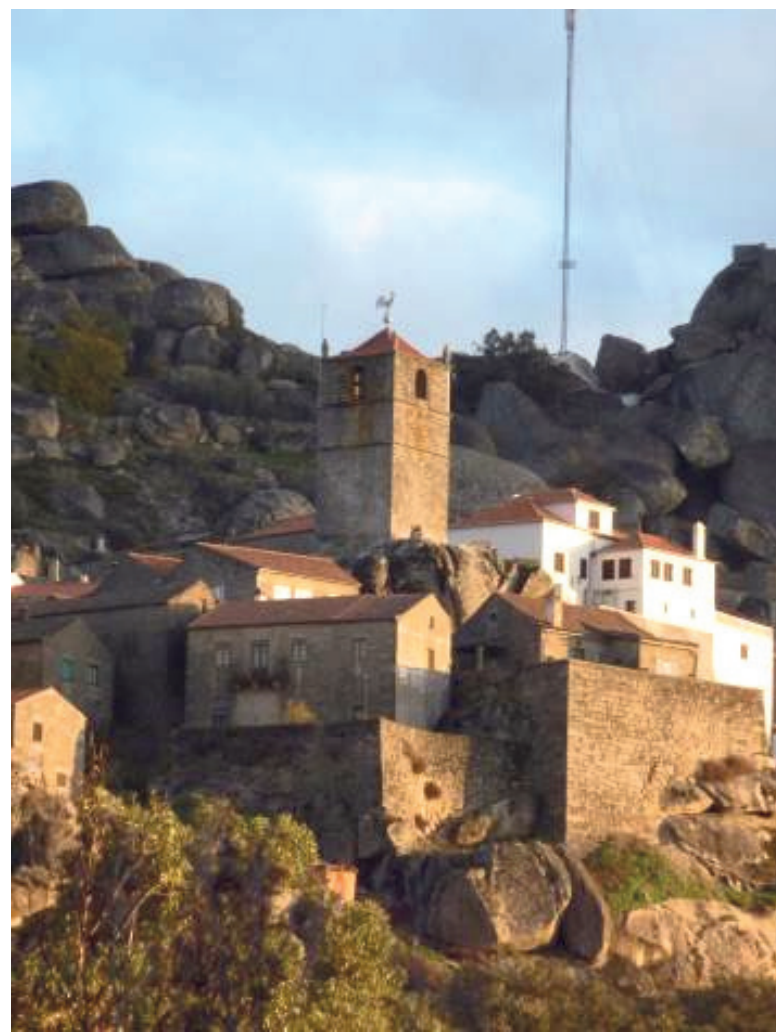

Figura 07 Villa de Monsanto, Portugal, 2013 (Imagen del autor) que adiciona la escala urbana, reflejando los diferentes poderes y los ejes de composición urbanos, las líneas donde la política y la visibilidad, conjugada con la topografía del lugar, asumen un camino y una identidad. Específicamente en el caso de la península ibérica, la topografía inclinada marca unas pautas en sus estrategias de defensa, siendo esto una característica de las aldeas, villas y ciudades de Portugal, teniendo una matriz común medieval, donde con un gran trabajo manual, los lugares más altos fueron los primeros en construirse, formando una silueta urbana defensiva consistente.

Rosa (2002, , pág. 244) habla sobre estas características de las ciudades portuguesas en los siguientes términos: "...de la nueva dinámica de D. Manuel I, es la del rey que cambio el castillo por la ribera, lo alto por lo bajo. Es para la historia del urbanismo portugués el paradigma... por nueva centralidad...".

El camino de esta búsqueda se basa en el presunto silogismo, que el arquitecto más habilitado para una determinada intervención será aquel que ha sacado mejor partido de su conocimiento sobre el lugar. Estos elementos son esenciales para el inicio de una intervención y para el desarrollo de estudios multidisciplinares, que sin estos no sería posible una intervención acertada "...sin la profundidad critica que pueda, eventualmente, llevar a la creación de medidas urbanísticas de esos bienes protegidos y de los respectivos contextos..." (Lopes, 2012, Pág. 124). Esta fórmula hiperbólica ejerce un efecto estimulante, siendo testigos arquitectónicos de una época que nos acompaña la vida, fruto del combate y de una expresión libre, frente a los problemas cotidianos, y también frente a esos lugares que son el patrimonio, que nos dan la alegría para vivir!. 


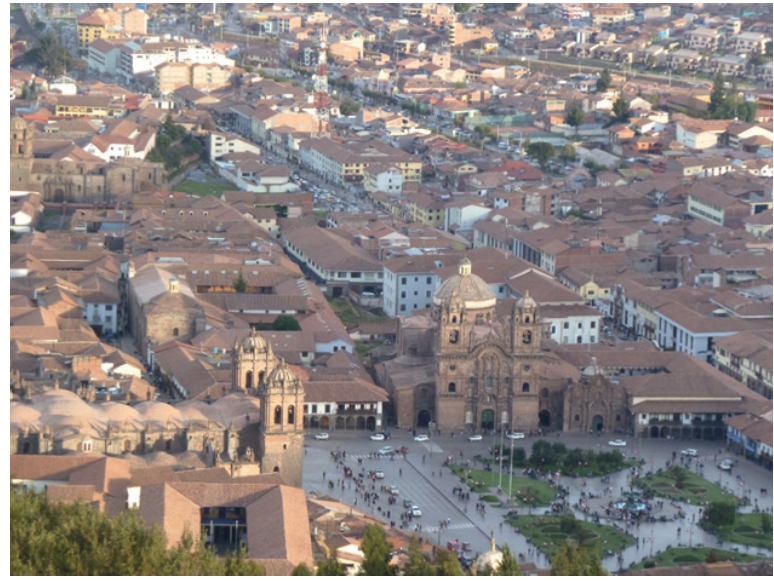

Figura 08 Vista de conjunto, Cuzco (Imagen del autor)

\section{METODOLOGÍA}

La metodología de este estudio, de enfoque interpretativo, se apoya en la estructuración de 3 ejes fundamentales de intervención:

Eje uno - Felicidad del espacio publico

Eje dos - Movilidades integradas

Eje tres - Anti polis + desarrollo al oriente

Estas líneas de intervención no son cerradas, por lo que deben ser estudiadas en conjunto, y por un equipo multidisciplinar, enmarcado en una perspectiva, y un nuevo paradigma holístico en el estudio de los procesos urbanos.

\section{RESULTADOS}

La gran mayoría de los procesos urbanos, siempre tuvieron una base defensiva (ocupación de los puntos altos) y una necesidad básica del agua, así encontramos un proceso histórico evolutivo donde el patrimonio histórico evolutivo, el patrimonio arquitectónico, y su sustentabilidad armonizaron durante varios siglos, legados que Ilegan hasta el siglo XXI, obteniendo con su memoria un lectura más equilibrada desde su evolución, creando ambientes y un vida feliz para sus habitantes.

Aun así, en el siglo XXI, estas ciudades necesitan con urgencia de una gran intervención a nivel de la regeneración urbana. Sobre todo las áreas degradadas,

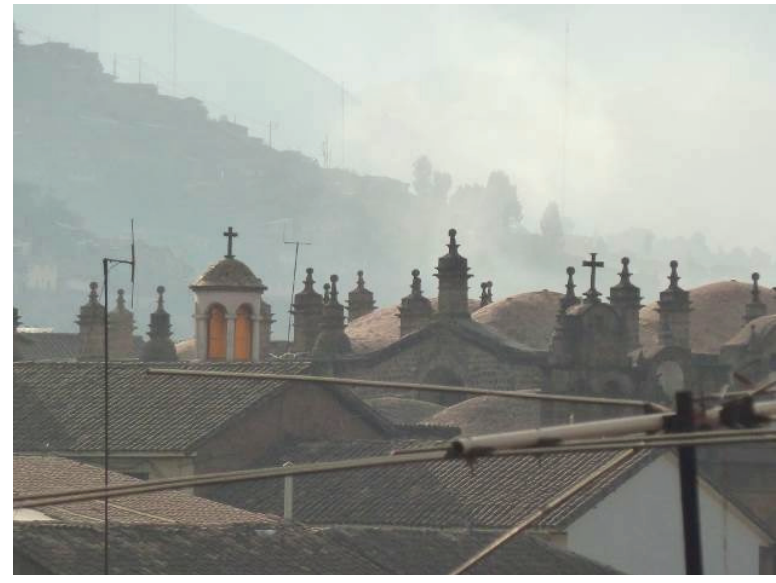

Figura 09 Detalle de los tejados, Cuzco, 2011 (Imágenes del autor)

en las cuales se encuentra una población envejecida y con problemas económicos; también jóvenes, con problemas de empleo y la dependencia económica de los mayores, siendo esto una situación preocupante en 2013, por lo menos en Europa.

Los suburbios de los años 60 y 70 no tienen ya las características de lo que se puede considerar la ciudad tradicional, esto debido al permanente desarrollo económico, además de la influencia y clara interpretación de las teorías urbanísticas modernas, lo que nos lleva a un nuevo caso

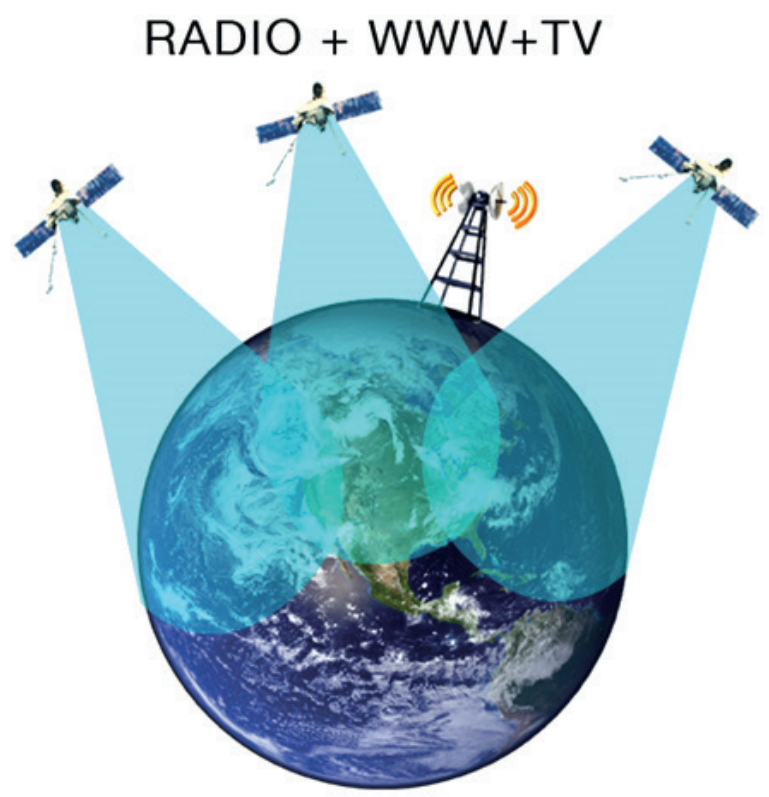

Figura 10 Ciudad digital,2011 (Imagen del autor) 
problemático; la malla urbana, ahora más amplia, y la movilidad peatonal, pasó a ser una movilidad de máquinas contaminantes, originando ambientes y fragmentos de ciudad, donde ya no existe el interés en vivir.

Observaremos ahora, la reflexión de estas problemáticas, desde los ejes de intervención, que trazamos para el estudio:

\section{Eje uno. Felicidad del espacio público}

La felicidad del espacio público y del ambiente urbano apenas será posible si se integra con una rehabilitación socioeconómica, particularmente difícil con la realidad económica por la que atraviesa Europa, pero es precisamente por eso que es más apremiante, no sólo para la dinámica inicial, sino principalmente por su mantenimiento. Esa situación no puede, en ningún momento poner en duda la necesidad de valorizar y salvaguardar el patrimonio cultural construido, por el contrario será una consecuencia de un proceso adecuado y sólidamente elaborado de preservación y rehabilitación del patrimonio.

Los estudios urbanos deberán ser amplios en sus objetivos, debidamente fundamentados, respetando la memoria de las comunidades, pero siendo capaz de reinventar el futuro de los espacios, en donde se desea habite un organismo vivo y dinámico, que necesita tener la capacidad de adaptarse a los cambios de hábitos, de necesidades y oportunidades de cada tiempo.

La revitalización socio-económica deberá ser causa y efecto, promover y ser promovida por la cohesión e inclusión social, en estos núcleos hoy habitados por una población envejecida, y cada vez con menos recursos, con características y necesidades muy particulares.

Se trata de poblaciones que viven el espacio público intensamente, pues ahí encuentran las posibles alternativas al aislamiento y soledad de sus casas. Pero, cada vez lo hacen con más dificultad por la progresiva pérdida de independencia, así como por la pérdida de valor de las relaciones de vecindad y de los lazos de responsabilidad con su comunidad.

Estos son elementos que no pueden ser ignorados en la rehabilitación, y en la felicidad en el espacio público, en el estudio de las accesibilidades, y de las condiciones de movilidad, en el diseño de la malla urbana o en la rehabilitación de las edificaciones. El involucrar la población de la tercera edad en las actividades e iniciativas comunitarias, deberá tener en consideración las necesidades de promover iniciativas que tengan como objetivo compartir costumbres y tradiciones entre los diferentes niveles etarios, pero también entre etnias que habitan ese espacio, todo esto en un proceso de integración de las minorías.

Más allá de la importancia del espacio urbano y del patrimonio construido, la memoria colectiva de estos núcleos será llenada aún por historias, olores y sabores, que marcan esos lugares como si fueran únicos y diferentes; y es la población más anciana, el principal medio de difusión de ese conocimiento, no pudiendo su papel, ser relegado a un plano secundario en la diferenciación y caracterización de la identidad cultural de un centro histórico de una ciudad que quiere ser integral.

La valorización del patrimonio cultural deberá partir de la identificación y valorización de las particularidades de la cultura local, involucrando la población y reinventándola. La valorización del Patrimonio Cultural existente y la promoción de su visibilidad serán consolidadas por su integración en las iniciativas locales, apoyadas en el conocimiento y divulgación de la información sobre los mismos y sobre los monumentos históricos de estos núcleos.

"...La experiencia especial propia de la Arquitectura se prolonga en la ciudad, en las calles y plazas, parques, estadios y jardines, donde la obra del hombre haya limitado vacíos, o sea, haya delimitado espacios cerrados..." (Toussaint, 2012, pág. 72) 
La necesaria y deseable eventual promoción turística, como potencial dinamizador de una revitalización económica, será una consecuencia natural de la madurez de una actividad cultural volcada hacia la población, pero será también el resultado previsible de apreciar y salvaguardar los centros históricos, ricos en patrimonios. La salvaguarda y protección de la morfología existente, de las escalas urbanas propias de esos centros históricos y de sus conjuntos edificados, permitirá un análisis interpretativo de los trabajos de levantamiento y de investigación histórica.

El objetivo es el de crear mejores condiciones de confort en el uso del espacio público, salvaguardando las características y la imagen de la estructura de las diferentes etapas de la historia urbana.

\section{Eje dos. Movilidades integradas.}

La creación de accesibilidades periféricas deberá privilegiar la circulación peatonal y la mejora de las condiciones de accesibilidad y movilidad inclusiva, fundamentales para el suceso de esta intervención. Uno de los principales problemas del área de intervención es el aparcamiento. Muchas de las vías locales y espacios públicos en los centros históricos no están adaptadas al tráfico motorizado.

El aparcamiento en la periferia de la zona de intervención es una alternativa a ser estudiada, con la creación de zonas de aparcamiento conectadas al centro histórico por caminos más o menos extensos, pero que sean interesantes y estimulantes. En cualquier caso, la creación de aparcamiento subterráneo o en altura en el centro resulta fundamental.

Deberán identificarse las principales conexiones peatonales con la malla urbana periférica, que deberán ser calificadas, generando caminos con ritmos diferentes de circulación, pero también espacios de escala urbana.

En el estudio del mobiliario urbano y señalética, se deberá poner particular preocupación, a la inclusión de personas con movilidad condicionada, así como otro tipo de discapacidades, convirtiendo los centros históricos en espacios inclusivos, abiertos, y atrayentes para todas las personas, con todas sus necesidades especiales. La creación de accesibilidades periféricas, deberán privilegiar la circulación peatonal, el transporte colectivo no contaminante y la mejora de las condiciones de accesibilidad y movilidad inclusiva, fundamentales para el suceso de esta intervención.

Uno de los principales problemas de las diferentes áreas de intervención en las ciudades ibéricas y latinoamericanas es el aparcamiento. Muchas veces las vías locales y los espacios públicos en los centros históricos no están adaptados al automóvil.

Un estudio de la movilidad y optimización del sistema vial, de modo que garantice el fácil acceso de las personas a los diferentes núcleos históricos, es un trabajo complejo y contempla varias condicionantes: la reordenación de la circulación vial, de modo que mejore la accesibilidad a través de la conexión entre los diferentes sistemas de transporte, ordenar el aparcamiento, y en el contexto de la red vial urbana y del sistema de transporte de la ciudad, establecer rutas que propicien la disponibilidad y disfrute del espacio público, privilegiando la circulación peatonal en los centros históricos. Hay que estudiar no sólo una circulación vial alternativa, sino también como prever el acceso de sus residentes, visitantes, comerciantes y servicios de emergencia, así como crear planos de riesgo para las situaciones de catástrofe natural o artificial, algo que no se piensa políticamente, pero que los académicos deben dar como aporte a las comunidades.

Eje tres. Anti polis + desarrollo al oriente Han surgido nuevas formas de ciudad, por un lado la gran industrialización a oriente (China), donde las poblaciones rurales pasan rápidamente al área urbana, creando una nueva dinámica de densidad urbana.

El factor tiempo reducido, en esta transferencia acelerada de millones de personas y de costumbres, algo nunca visto, inevitablemente desarrollará nuevos procesos urbanos, transformándose en una oportunidad para arquitectos y creadores de espacios, 


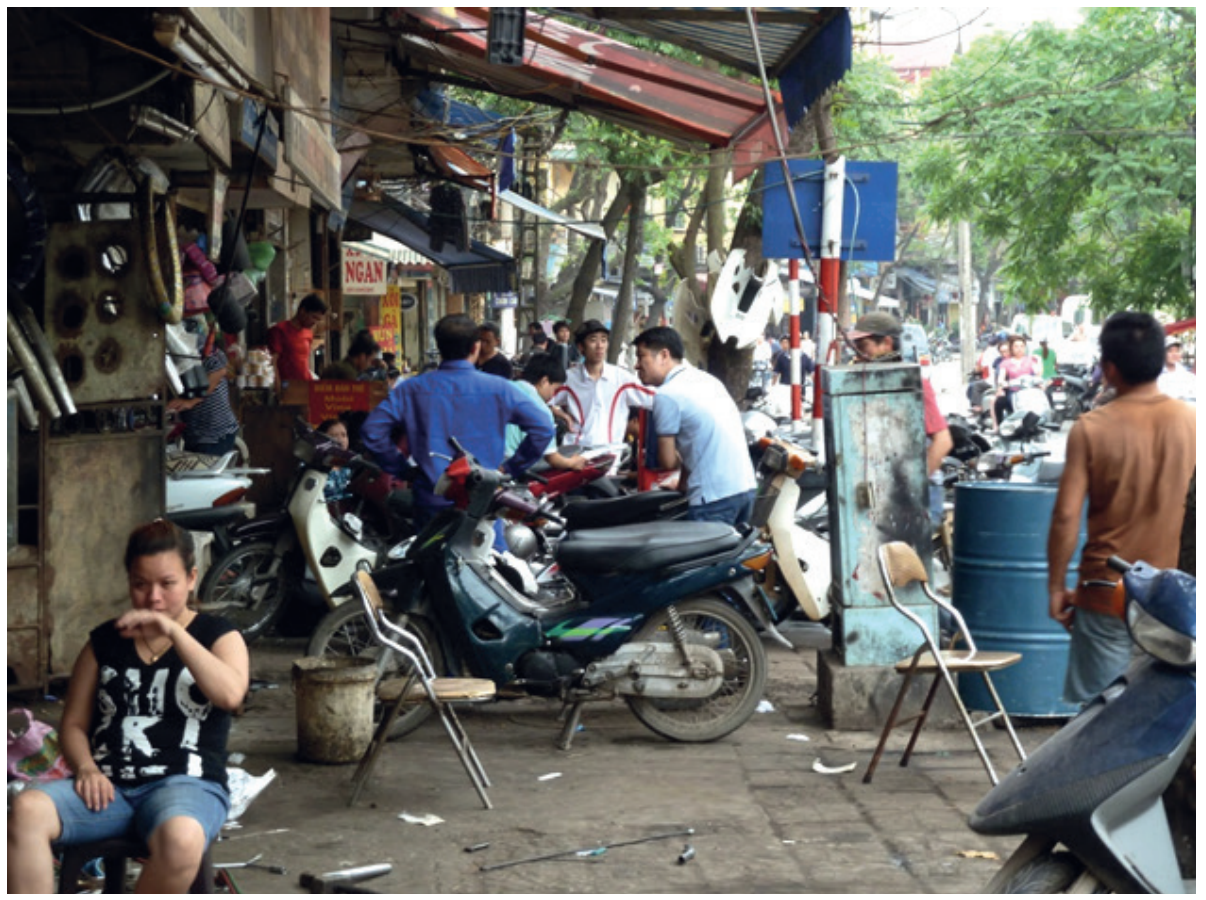

Figura 11 Ocupación de la calle. Vietnam, 2011 (Imágen del autor)

una nueva y diferente manera de pensar el diseño de la planificación urbana, una nueva y urgente respuesta única en la historia de la evolución urbana de las mega ciudades, que nacerán en un futuro muy cercano.

Por otro lado encontramos otro fenómeno a surgir más concretamente en EEUU, específicamente en la zona sur, un nuevo concepto de ciudad, la anti polis, o ciudades ambulantes que se montan y desmontan, en función de los ciclos de desarrollo económico y político, con transferencias rápidas para otros territorios, dando respuesta a gran movilidad de la población.

Este tipo de ciudades, que aparecen y desaparecen, existen en el sur de California, Arizona, Houston, Luisiana, Tennessee, Mississippi, Alabama, y Georgia, reflejando la gran mutabilidad, falta de cohesión y de sentido de ciudad, con una pérdida de diversidad y vivencia del espacio público. Las suburbias, de que habla Vásquez (2011)

"...Lo que explica este desfase es el modelo urbano que las metrópolis del cinturón del sol eligieron para materializar su espectacular desarrollo: suburbia. (Basado en la baja densidad) consume mucho más territorio. Los Ángeles, por ejemplo, necesita siete veces más suelo que Brooklyn para albergar al mismo número de habitantes..." (Vásquez, 2011, Pág. 13).

La construcción de nuevos edificios ocupando vacíos urbanos o en sustitución de ocupaciones no consonantes con el ambiente general, en las situaciones previstas o planificadas, deberán obedecer a condicionantes como la volumetría, la alienación de los planos de fachadas, profundidad de ocupación y reglas de composición arquitectónica. Adicionalmente deberá existir una preocupación por prever el espacio para aparcamiento, siempre que eso sea viable.

En una perspectiva de rehabilitación integrada, la resignificación del espacio urbano y del patrimonio construido, apenas es viable si son desarrolladas en conjunto acciones de rehabilitación de la estructura social y de mejora de la calidad de vida de la población, basadas en una revitalización socio-económica y cultural. Debe existir una 


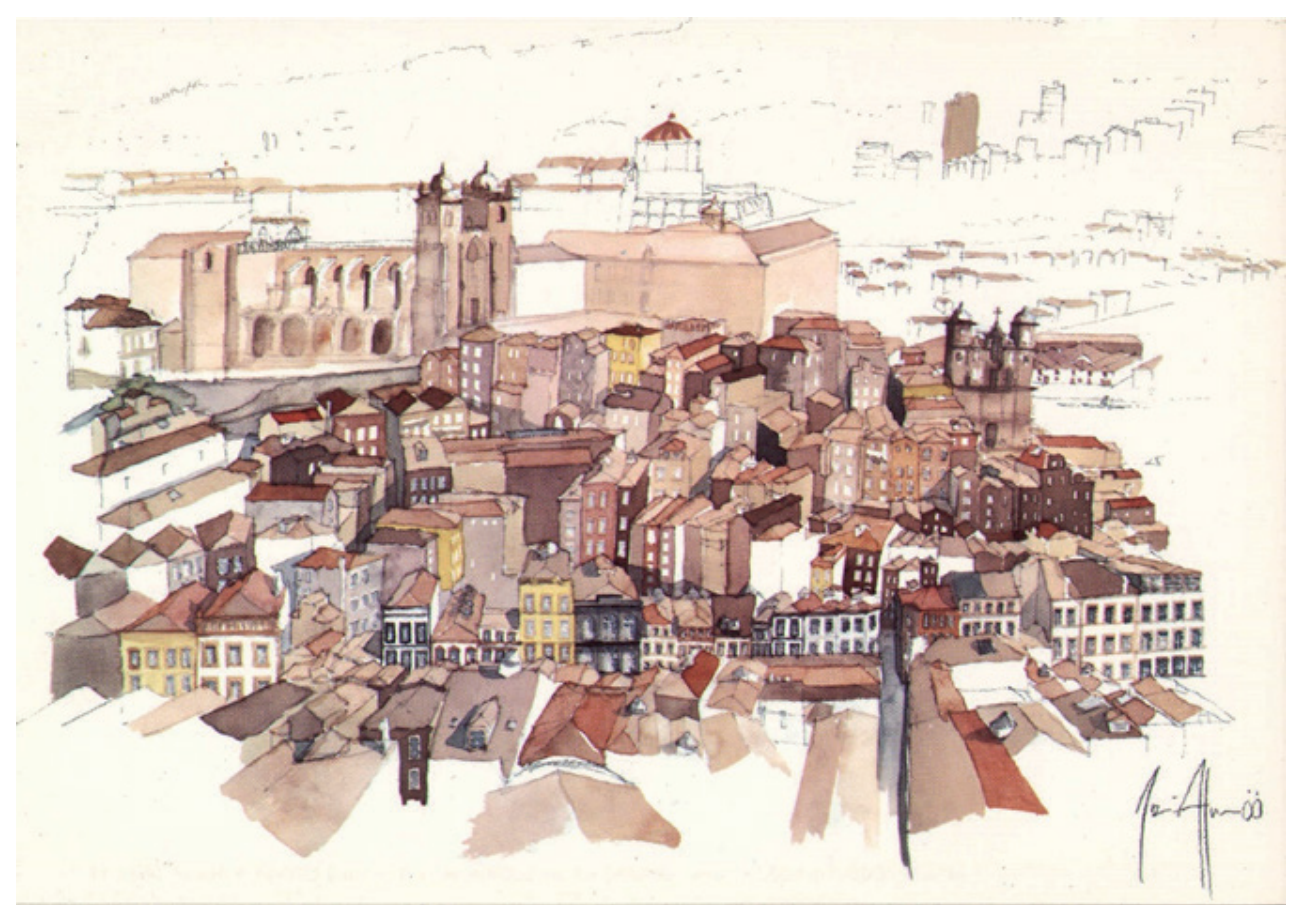

Figura 12 Acuarela, Oporto, Portugal, 1988 (Imagen del autor)

identificación del individuo con el espacio público, que debe ser diseñado a la medida de las necesidades de sus usuarios.

El espacio público deberá ser construido con legibilidad y durabilidad, proporcionando interacciones entre las personas y el espacio público, y viceversa. La intervención en el espacio público deberá contemplar la modernización de las infraestructuras, jamás con una estrategia mono funcional y con concepto de anti polis que destruye la tradición del crecimiento de nuestras ciudades latinas tan emotivas y llenas de vida.

\section{CONCLUSIÓN}

Necesitamos de una ciudad volcada para las personas, desarrollando gradualmente una política ecológica de movilidad, rehabilitando los centros históricos como un área de atracción para peatones, manteniendo los estándares de calidad ambiental de antes.

El espacio público deberá incorporar una gran diversidad de mobiliario urbano, de iluminación y de pavimentación pensada y diseñada. No deberá existir una paleta restricta de materiales o un patrón único en el lenguaje urbano. Por el contrario, cada espacio deberá ser diseñado como un lugar único en su génesis, con una identidad propia, marcada por sus vivencias, por su historia, por sus memorias, pero también por sus potencialidades de reinventarse, lo más diversificada posible.

Será necesario en esta evolución que se avecina, no olvidarnos de las personas y de su alegría de vivir en ambientes agradables. El diseño del espacio urbano implica crear atmosferas donde la naturaleza humana tenga un espacio físico equilibrado, idonde vivir es casi como estar en el paraíso!

"...Tenemos para con los campos la obligación de que nuestras casas no sean inferiores al terreno virgen que ellas substituirán. Debemos a la vegetación, a los árboles, que los edificios con los que los cubrimos se erijan como promesas de las más elevadas y de las más inteligentes formas de felicidad..." (Botton, 2006, Pág. 304) 
PROCESOS URBANOS - Revista de Divulgación Científica Vol. 1 Enero - Diciembre 2014 (7 - 16)

\section{REFERENCIAS}

Botton, Alain de (2006). The architecture of happiness, Lumen. Pág.304

Dias, Manuel Graça (2006). Manual das Cidades, Relógio d'Água, Pág.73

Lopes, Flávio (2012) Patrimonio Arquitectónico e Arqueológico, Caleidoscopio, Pág.124.

Rosa, Walter (2002) A Urbe e o Traço, uma década de estudos sobre o urbanismo portugues. Lisboa: Almedina, Pág.247; Pág.244
Toussaint, Michel (2012) Da Arquitectura à Teoria. Teoría da arquitectura na primeira metade do seculo XX. Caleidoscópio, pp72

Vásquez, Carlos Garcia (2011) Antípolis. El desvanecimiento de lo urbano en el Cinturón del Sol. Gustavo Gili, Barcelona. 2011, Pág.13 